\title{
INSTITUCIONALIZAÇÃO DA ASSEMBLEIA LEGISLATIVA DO ESTADO DE SÃO PAULO (ALESP): EVIDÊNCIAS DE UM PARLAMENTO SUBNACIONAL BRASILEIRO ${ }^{12}$
}

Danilo Cesar Fiore ${ }^{3}$

\begin{abstract}
Resumo
O artigo procura mensurar o grau de institucionalização da Assembleia Legislativa do Estado de São Paulo (ALESP), no período recente, a partir de indicadores consagrados da literatura em Ciência Política. Além de uma breve revisão teórica sobre o conceito, são apresentados resultados empíricos que demonstram crescente institucionalização desse Poder Legislativo subnacional. Ao final, são discutidas as implicações dos achados, a partir da crítica à própria noção de institucionalização e de sua aplicação para a compreensão da dinâmica do sistema político e federativo brasileiro.
\end{abstract}

Palavras-chave: institucionalização; poder legislativo; ALESP; governos subnacionais.

\begin{abstract}
This article intends to measure the degree of institutionalization of São Paulo's Legislative Assembly in recent years. It does so by using indicators present in the Political Science specialized literature. Aside from a brief theoretical review, the article also presents empirical results demonstrating the increase of institutionalization in the legislative body. In the end, we discuss the implications of these findings through a critical view of the notion of institutionalization and its use in understanding the dynamics of the Brazilian political and federative system.
\end{abstract}

Keywords:institutionalization; legislature; ALESP; subnational governments.

\section{Resumen}

El artículo trata de medir el grado de institucionalización de la Asamblea Legislativa del Estado de São Paulo (ALESP) en el período reciente a través de los indicadores reconocidos por la literatura de Ciencias Políticas. A partir de una breve revisión teórica del concepto, se presentan los resultados empíricos que demuestran el aumento de la institucionalización de este Poder Legislativo subnacional. Por último, se discuten las implicaciones de los resultados a partir de la crítica de la noción misma de institucionalización y de su aplicación a la comprensión de la dinámica del sistema político y federativo brasileño.

Palabras-clave:institucionalización; poder legislativo; ALESP; gobiernos subnacionales

\section{INTRODUÇÃO: UM BREVE BALANÇO TEÓRICO}

O objetivo deste trabalho é mensurar o nível de institucionalização da Assembleia Legislativa do Estado de São Paulo (ALESP), no período recente, a partir da análise de indicadores consagrados na literatura, tais como índice de renovação (turnover), experiência de lideranças e recursos disponíveis para a organização.

\footnotetext{
${ }^{1}$ DOI deste artigo: http://dx.doi.org/10.5380/recp.v5i2.37150

2 Agradeço ao professor Timothy Power (Oxford University) pelos comentários à versão preliminar deste trabalho, bem como ao parecerista anônimo do periódico pelas recomendações prévias à publicação. Agradeço, ainda, a Marian Salles Gomes Bellamy e Felipe Teixeira Gonçalves pelo auxílio na revisão idiomática dos resumos em inglês e espanhol, respectivamente.

${ }^{3}$ Mestrando em Ciência Política pela Universidade de São Paulo (DCP/FFLCH/USP).
} 
Este artigo está estruturado em três seções: um breve balanço teórico introdutório sobre o conceito de institucionalização e sua aplicação para os estudos legislativos; análise do Poder Legislativo do Estado de São Paulo no período recente (sobretudo a partir de 1994), por meio do exame de cinco indicadores selecionados; considerações finais sobre os dados coletados e contribuições referentes ao debate sobre o tema.

$\mathrm{O}$ interesse pelo estudo de caso legislativo em contexto subnacional advém do predomínio de artigos e pesquisas focados no caso do Congresso Nacional Brasileiro, sobretudo da Câmara dos Deputados. Com efeito, o debate acerca das relações entre Executivo e Legislativo, no Brasil, e o papel deste último no novo arranjo constitucional pós-1988 teve centralidade na ciência política brasileira ao longo das duas últimas décadas.

Não convém retomar este debate em pormenores, portanto ele será apresentado de forma resumida ${ }^{4}$. No contexto da promulgação da Constituição Federal de 1988, uma série de autores manifestou dúvidas a sobre a capacidade decisória do Executivo e os custos para a formação de maiorias em um cenário de aguda crise socioeconômica, multipartidarismo e elementos institucionais com potencial fragmentador - tal como o voto proporcional em lista aberta para o Legislativo associado ao voto majoritário para Presidente.

Em resposta, diversos estudos procuraram demonstrar que tais receios não teriam se concretizado, tendo em vista a presença de mecanismos institucionais (tais como medidas provisórias e o papel das lideranças partidárias no Congresso, por exemplo) que propiciariam condições e incentivos para formação de maiorias a um custo compatível com a governabilidade.

A centralidade do tema da dinâmica entre Executivo e Legislativo no processo decisório permanece (seja nos estudos acadêmicos, seja no noticiário político), tendo em vista as recorrentes e usuais tensões vividas na relação entre os poderes. Os estudos sobre institucionalização legislativa, todavia, têm ganhado maior destaque.

O conceito de institucionalização aplicado a parlamentos foi definido por diversos autores. Polsby (1968) o caracteriza da seguinte maneira: presença de fronteiras com relação ao ambiente que cerca a instituição, fazendo com que seus membros apresentassem aspectos peculiares e fossem selecionados a partir de processos minimamente criteriosos além de suas lideranças serem escolhidas internamente; complexidade interna e divisão do trabalho, com maior especialização e interações relativamente independentes entre os

\footnotetext{
4 Para além dos muitos artigos, teses e obras sobre o tema, ver os trabalhos fundamentais de ABRANCHES (1988), LAMOUNIER (1992), AMES (2000) e FIGUEIREDO \& LIMONGI (1999), que serviram de base para esta sucinta apresentação.
} 
setores e membros que compõem o órgão; e, por fim, a prevalência de critérios universais sobre métodos discricionários na condução dos negócios internos - ou seja, meritocracia e padronização de procedimentos em detrimentos de "ad-hocracia" e favoritismos ${ }^{5}$.

Pallanza et alli (2012) apresentam uma visão de institucionalização legislativa como fenômeno de equilíbrio, em que crenças e ações dos atores (internos e externos à organização) na capacidade e relevância da instituição os levam a investir mais ou menos nesta arena. Assim, o processo tenderia a se retroalimentar, posto que, quanto mais institucionalizada a arena legislativa (ou seja, mais capacitada e com poder decisório), maiores os investimentos dos atores.

Luz (2009) enfatiza a importância do vínculo entre institucionalização e democracia. Neste caso, a conexão entre eleitores e representantes por meio de diferentes formas de accountability possibilitaria o incremento contínuo da capacidade de atuação dos parlamentos.

Para Hibbing (1988), o conceito de institucionalização está vinculado à ideia de mudança institucional: ao longo do tempo, instituições tendem a adotar certas características e perder outras. Em linhas gerais, uma instituição típica tende a tornar-se mais complexa, autônoma, coerente, adaptativa e com critérios internos universais. Por outro lado, o autor salienta a abrangência do termo - razão pela qual o define como um "conceito guarda-chuva", que pode abarcar tendências ecléticas em determinada direção.

Em termos normativos, seria a institucionalização de parlamentos algo desejável? Para Polsby (1968), a institucionalização seria essencial, pois, caso contrário, o sistema político tenderia a instabilidade, fraqueza e incapacidade de responder às demandas ou proteger os grupos que o compõem - o que, em última instância, afetaria sua própria essência democrática. Pallanza et alli (idem) secundam esta avaliação. Para os autores, parlamentos, órgãos judiciários ou partidos, ou outros organismos políticos, se institucionalizados, teriam maior capacidade de implementar políticas públicas efetivas. Sendo o parlamento uma instituição crítica para o funcionamento da democracia, seu fortalecimento / institucionalização tenderia a contribuir de maneira decisiva para o processo de formulação e execução de melhores políticas públicas. Hibbing (1999), por outro lado, considera a institucionalização, enquanto argumento teórico, desejável. Levanta, porém, algumas considerações sobre a possibilidade de aplicar automaticamente o conceito (ou um modelo deste) a contextos socioeconômicos e institucionais diversos ${ }^{6}$.

\footnotetext{
${ }^{5}$ Idem, p. 145.

${ }^{6}$ Algumas das contraposições de Hibbing (1988) são apresentadas na última seção deste artigo.
} 
A mensuração do nível de institucionalização a partir de indicadores e modelos teóricos se encontra em diversos estudos de caso presentes na literatura.

O trabalho seminal de Polsby (1968) tem grande influência no campo de estudos legislativos. A partir da análise de determinados indicadores da U.S. House of Representatives (a Câmara dos Deputados americana), tais como a taxa de renovação dos mandatos (presença de novos parlamentares a cada legislatura), tempo médio de serviço dos legisladores, a experiência prévia dos legisladores que se tornaram speakers ("presidentes"), os recursos financeiros disponíveis à instituição, entre outros, o autor procura identificar tendências de institucionalização neste órgão. Segundo o mesmo, as taxas decrescentes de renovação e crescentes de tempo médio de mandato, recursos disponíveis e experiência dos líderes demonstrariam o caráter altamente institucionalizado da "câmara baixa" do Legislativo americano.

Hibbing (1988) analisou de forma análoga a House of Commons do Reino Unido. Utilizando-se de alguns indicadores semelhantes (taxa de renovação, recursos financeiros despendidos e experiência dos líderes), o autor identifica um grau elevado de institucionalização do parlamento britânico - algo porventura inesperado, posto o caráter "híbrido"” da instituição. Por outro lado, ele aborda a importância de serem considerados alguns elementos - como o regime de governo e o nível de desenvolvimento econômico que podem influenciar o processo de institucionalização, o que o torna não uniforme, monotônico ou homogêneo.

Com relação ao contexto subnacional, há uma série de trabalhos norte-americanos acerca de legislativos estaduais. Vale destacar, a título de exemplo ${ }^{8}$, o extenso estudo comparativo de Squire \& Hamm (2005) sobre os parlamentos estaduais e o Congresso dos EUA, tentando observá-los em conjunto ao longo do tempo a partir de três eixos de análise: características institucionais, características organizacionais e carreiras dos legisladores.

No caso brasileiro, Luz (2009) analisa o caso de uma assembleia sui generis (sobretudo por ter atribuições de uma câmara municipal e de uma assembleia legislativa estadual) e instalada apenas recentemente (1991), a Câmara Legislativa do Distrito Federal. O autor constrói um modelo de estudo baseado no exame de seis componentes: instrumentos de interação com a sociedade civil; insulamento burocrático (corpo funcional da Casa); aderência às regras constituídas (relação dos parlamentares com o Regimento

\footnotetext{
7 Por ser um regime parlamentarista, o Parlamento britânico compõe dois poderes, o Executivo e o Legislativo - o que, segundo o autor, se traduz em diferenças significativas para com um congresso em regime presidencialista tal qual o norte-americano ou o brasileiro. (HIBBING, 1988, p. 683).

8 Ver também CHAFFEY (1970), SQUIRE (1992) e ROSENTHAL (1996).
} 
Interno); complexidade interna e divisão dos trabalhos; pluralismo, traduzido na possibilidade de voz às minorias; e autonomia funcional (relação Executivo-Legislativo). Para o autor, a Câmara ainda possui uma longa jornada de desenvolvimento institucional, mas apresentou avanços consideráveis no período recente.

\section{INDICADORES DE INSTITUCIONALIZAÇÃO DA ALESP}

Nesta seção serão expostos e analisados alguns indicadores de institucionalização aplicados ao caso da Assembleia Legislativa do Estado de São Paulo no período recente sobretudo da $13^{\mathrm{a}}$ à $17^{\mathrm{a}}$ Legislaturas (1995-2015). Em consonância com a literatura abordada na seção anterior, foram selecionados cinco eixos de análise: taxa de renovação dos membros do parlamento (turnover); experiência prévia das lideranças; recursos disponíveis; nível de disputa pelas cadeiras; e presença de mulheres no parlamento.

Taxa de Renovação (Turnover)

Indicador de institucionalização comumente utilizado, a taxa de renovação se refere ao percentual de membros ingressantes em uma organização a cada determinado período (no caso de Legislativos, a cada pleito). Uma organização com nível de rotatividade menor poderia ser considerada mais institucionalizada por duas razões: nível significativo de prestígio de seus integrantes, que procurariam nela permanecer; e retenção de conhecimentos e experiências, o que possibilitaria funcionamento mais produtivo da organização?

Para este indicador, foram coletados dados referentes aos cinco últimos pleitos para deputado estadual em São Paulo (1994 a 2010). A taxa de renovação foi obtida a partir da divisão de novos membros (em relação ao pleito anterior) pelo total de membros eleitos na eleição observada. Destaque-se que a Taxa de Renovação para o ano de 1994, em relação ao ano de 1990, deve ser lida com cautela, uma vez que naquela eleição o número de cadeiras em disputa saltou de 84 para 94 - tornando esperadamente maior a porcentagem de renovação encontrada (ALESP, 1998).

Os índices encontrados seguem no quadro 1 abaixo. Para fins de comparação, foram incluídos também dados referentes à Câmara dos Deputados Federal para o mesmo período:

${ }^{9}$ PALLANZA et alli, (2012), p. 12. 


\begin{tabular}{|c|c|c|c|c|c|}
\hline \multicolumn{7}{|c|}{ QUADRO 1 - TAXA DE RENOVAÇÃO (TURNOVER) DA ALESP EM CADA } \\
ELEIÇ̃̃O \\
\hline Eleição & $\mathbf{1 9 9 4}$ & $\mathbf{1 9 9 8}$ & $\mathbf{2 0 0 2}$ & $\mathbf{2 0 0 6}$ & $\mathbf{2 0 1 0}$ \\
\hline Novos membros (N) & 61 & 50 & 47 & 49 & 35 \\
\hline Taxa de Renovação (\%) & $64,9 \%$ & $53,2 \%$ & $50,0 \%$ & $52,1 \%$ & $37,2 \%$ \\
\hline Câmara dos Deputados (\%) & $54,3 \%$ & $43,9 \%$ & $44,8 \%$ & $48,0 \%$ & $44,0 \%$ \\
\hline
\end{tabular}

Fonte: TSE; DIAP; elaboração própria.

Não obstante o valor elevado (e esperado) referente ao pleito de 1994, observa-se que a taxa de renovação do Legislativo Paulista foi estável ao longo dos três sufrágios seguintes (1998, 2002 e 2006), quando cerca da metade das cadeiras passaram a ser ocupadas por membros não eleitos nos pleitos anteriores. Estabilidade semelhante é encontrada na composição da Câmara dos Deputados, em que o nível de renovação manteve-se em torno de 45\% no período posterior a 1994. Destaque-se que, nesta eleição, assim como no caso da ALESP, o número de cadeiras de deputado federal em disputa também foi majorado (a bancada federal paulista, por exemplo, foi aumentada de 60 para 70 integrantes).

Verifica-se que, na última eleição, a taxa de renovação da ALESP sofreu uma queda expressiva. Não resta claro, porém, se este foi apenas um ponto fora da curva ou se a tendência será de maior permanência dos incumbentes nos futuros pleitos - o que, de acordo com a literatura, apontaria tendência de institucionalização do parlamento.

Em comparação com outros países, a taxa de renovação encontrada nos parlamentos brasileiros é francamente maior. No contexto subnacional americano, por exemplo, Squire \& Hamm (2005) apresentam dados segundo os quais a taxa de renovação média dos parlamentos estaduais americanos foi de 25\% nos anos 1990 (p.143). A taxa mais elevada, encontrada no Senado Estadual do $\operatorname{Kansas}^{10}$, foi de 43\% (cerca de 10 pontos percentuais a menos do que as taxas encontradas na ALESP no período). Leve-se em conta ainda que, segundo os mesmos autores, muitos Estados americanos limitam as possibilidades de reeleição dos representantes (o que indubitavelmente atua no sentido de aumentar o índice de renovação). No caso brasileiro, a reeleição é livre para os mandatos legislativos em todos os níveis.

O índice elevado de renovação encontrado na Câmara dos Deputados brasileira (e, como se vê, também presente em legislativo estadual) é explicado por SAMUELS (2000)

1049 dos 50 Estados americanos contam com câmaras altas e câmaras baixas, situação inexistente no panorama institucional brasileiro. 
como devido à ambição eleitoral dos legisladores, voltada para o Poder Executivo em razão da prevalência deste na condução de políticas públicas e na própria agenda legislativa. Nesse sentido, o parlamento seria tão somente um estágio prévio ou intermediário de carreira política dos atores. Outro fator apresentado é o sistema eleitoral brasileiro (proporcional de lista aberta), que propiciaria maior competição eleitoral e menores vantagens comparativas para os incumbentes.

Por fim, algumas considerações de ordem metodológica. Quando se trata de indicadores de renovação, é possível trabalhar com outras formas de mensuração de forma a mitigar eventuais limitações de análise. Por ser obtido a partir dos parlamentares eleitos na disputa eleitoral anterior, o indicador utilizado neste tópico não mensura, por exemplo, os suplentes que assumiram ao longo do mandato e que, porventura, tenham ganhado a eleição. Ainda a título de exemplo, também não mensura quantos deputados buscam a reeleição a cada pleito (medida que demonstra a ambição dos incumbentes por manterem suas cadeiras). Em resumo, há outras fórmulas que podem ser cotejadas para quadro mais detalhado de renovação do poder Legislativo ${ }^{11}$.

\section{Experiência prévia dos presidentes}

Uma forma de verificar a institucionalização de um parlamento é identificar os mecanismos de seleção interna de suas lideranças. Conforme visto na seção anterior, há um pressuposto na literatura segundo o qual a ascensão de lideranças com maior "tempo de casa” - ou que estejam no auge de suas carreiras - seria um indicador de maior profissionalização do poder legislativo.

No caso da ALESP, foram coletados dados de experiência parlamentar dos últimos 15 presidentes desde 1983 (data na qual foi eleita a primeira legislatura, após o fim do bipartidarismo imposto pelo Regime Militar de 1964). Conforme se verifica no gráfico 1, abaixo, apenas o primeiro presidente do período estava em sua primeira legislatura.

11 Silva Júnior \& Figueiredo Filho (2012) apresentam quadro comparativo dos índices de renovação comumente utilizados (p. 202). 


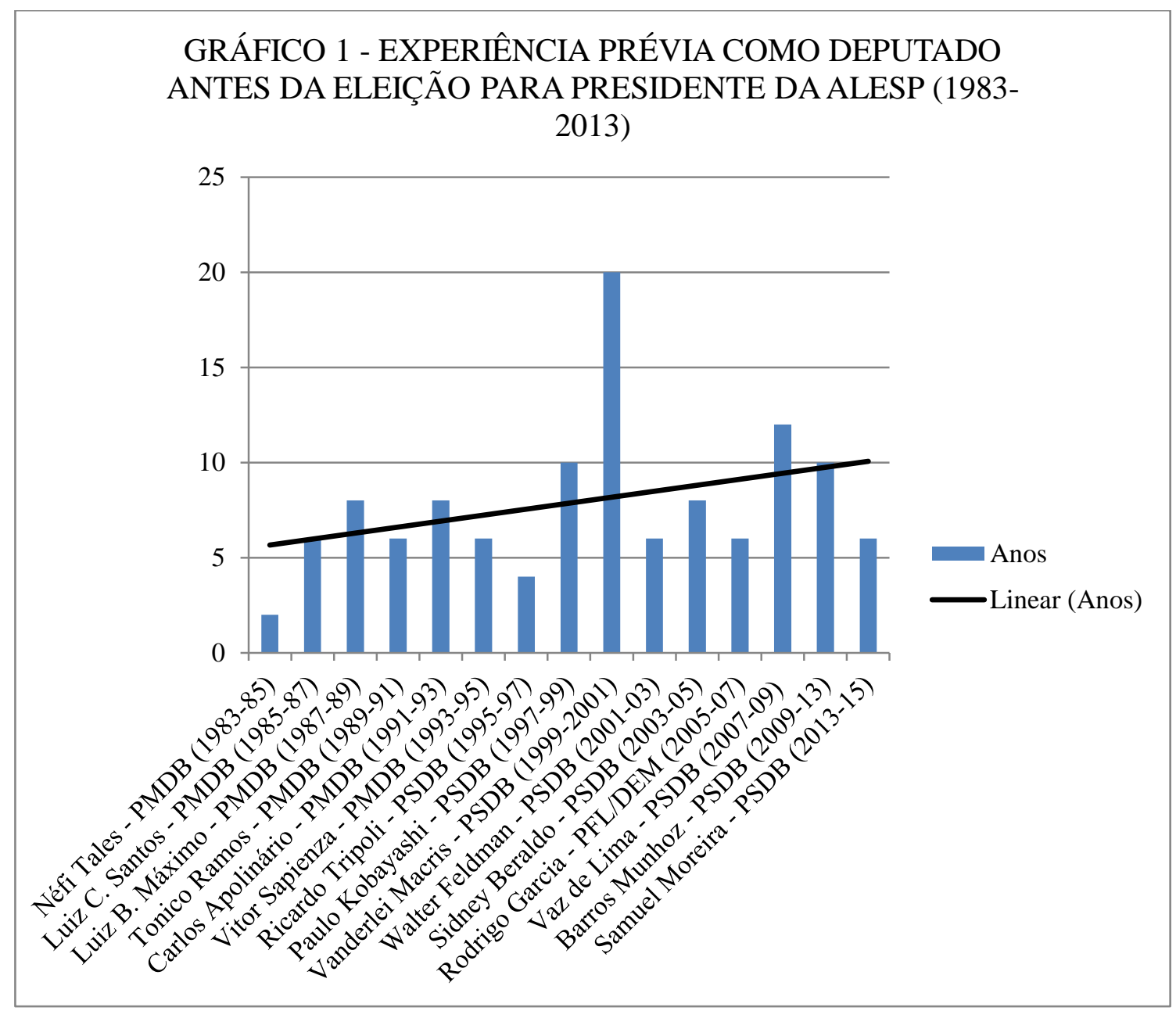

* Partido à época da eleição como presidente.

Fonte: ALESP (2006); elaboração própria.

Observa-se que a média de experiência dos parlamentares antes de atingir a presidência é de 7,8 anos de mandato. A mediana de 6 anos, próxima à média, parece demonstrar certa tendência de eleição para presidente na metade final do segundo mandato ${ }^{12}$. Percebe-se ainda uma tendência linear de aumento da média no período, o que caracterizaria, segundo a literatura,tendência de maior nível de institucionalização da ALESP.

Vale destacar que, ainda que com tendência de crescimento, o tempo de serviço dos presidentes do legislativo paulista são menores se comparados com pares de outros países. Enquanto no Reino Unido a média de tempo de serviço como parlamentar dos últimos 5 presidentes até 1983 era de 20 anos (HIBBING, 1988, p.692), nos EUA todos os speakers do século XX até 1962 tinham, no mínimo, 15 anos de experiência prévia como parlamentares (POLSBY, 1968, p 149).

12 Convém lembrar que a soma de anos de experiência não é linear, ou seja, os mandatos podem não ser seguidos. É o caso, por exemplo, de Barros Munhoz (deputado estadual entre 1987-1995 e 2007-2014). 


\section{Recursos da Instituição}

Outro indicador comumente utilizado de institucionalização é o volume de recursos despendidos pelo órgão ao longo do tempo. Em princípio, mais recursos (sobretudo financeiros) incrementam o potencial de atuação de um órgão, pois propiciam maior desenvolvimento de sua complexidade interna.

Para o caso da ALESP, foram utilizados dados de despesas orçamentárias anuais a partir de 1997 (primeiro ano com dados disponíveis). Os valores foram corrigidos em termos reais ${ }^{13}$ e divididos pelo número de deputados estaduais, de forma a mensurar o dispêndio per capita anual médio de cada legislador. Os dados seguem apresentados no gráfico 2 abaixo:

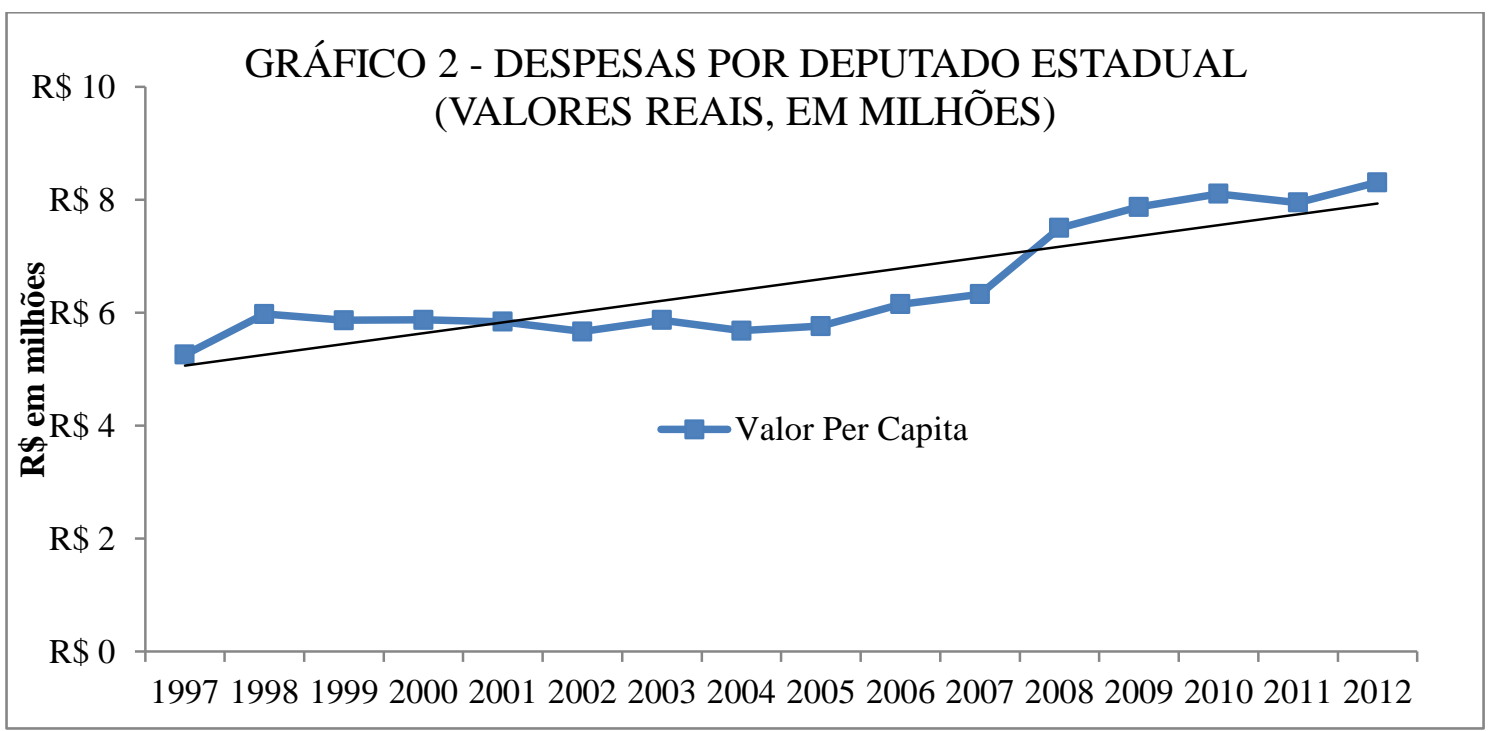

* Valor real das despesas orçamentárias anuais da ALESP, dividido pelo número total de deputados estaduais. Fonte: SIAFEM-SeFaz / SP

Como se pode depreender da análise do gráfico acima, no início da década de 2000 houve queda, em termo reais, nos recursos financeiros médios despendidos por parlamentar - tendência essa, porém, invertida na segunda metade da década, quando o volume de recursos foi majorado de maneira significativa. Ao longo do período, a tendência é de crescimento.

Para fins de comparação, foram coletados também dados de dispêndio orçamentário no mesmo período de outros dois "poderes" paulistas, o Judiciário e o

${ }^{13}$ Valores corrigidos pelo IPC-A/IBGE até Março de 2013. 
Ministério Público ${ }^{14}$. O objetivo é verificar se as tendências de crescimento orçamentário encontradas no caso da ALESP, conforme observado no gráfico 3, podem ser encontradas também em instituições "análogas".

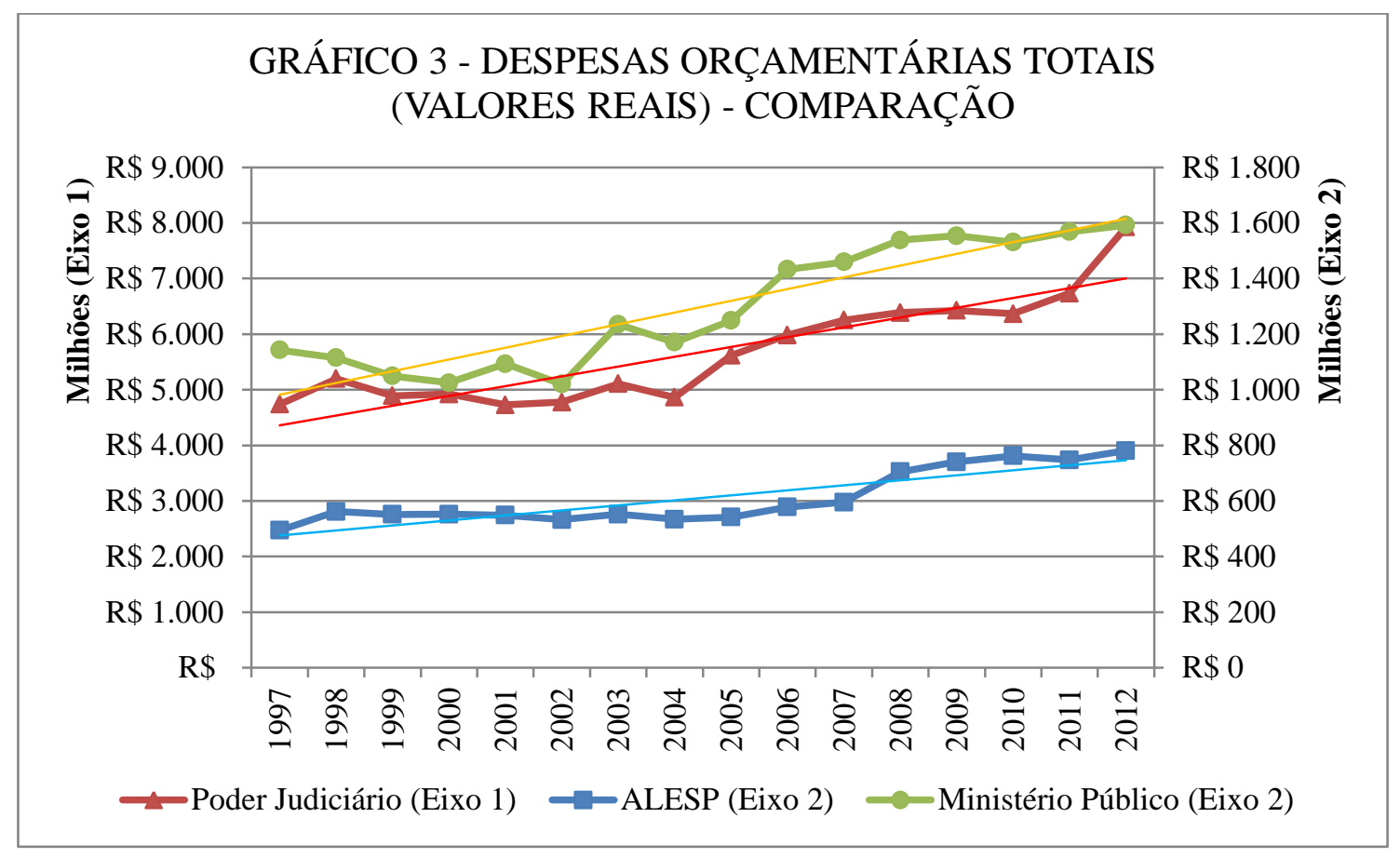

Fonte: SIAFEM-SeFaz/SP; valores corrigidos pelo IPC-A/IBGE até março/2013.

É possível verificar que os orçamentos do Ministério Público e do Poder Judiciário paulistas também tiveram tendência de crescimento no período (mais expressiva, inclusive, do que a da ALESP). Neste sentido, poder-se-ia dizer que a tendência de maior institucionalização do legislativo, se entendida como aumento dos recursos disponíveis a uma organização, foi acompanhada de movimento semelhante em outros poderes.

\section{Disputa pelas Cadeiras}

Outro indicador utilizado para mensurar o nível de institucionalização de parlamentos é o nível de competição para seleção de seus quadros. Entende-se que uma elevada competição para entrada na organização seria mostra de seu poder de atração, oriundo do prestígio e da profissionalização do corpo de integrantes. Por essa razão, este indicador é comumente associado à taxa de renovação: uma organização mais

14 Ainda que não seja um "Poder" no sentido estrito do termo, o Ministério Público assemelha-se aos três poderes em razão de sua autonomia funcional e administrativa, assegurada pelas Constituições Federal e Estadual. Para fins de análise de institucionalização, portanto, a comparação se mostra válida. Destaque-se, ainda, a grande quantidade de estudos recentes sobre o papel do Ministério Público no arranjo institucional brasileiro pós-1988. Ver ARANTES (2007). 
institucionalizada tenderá a atrair novos quadros, assim como seus integrantes buscarão nela permanecer ${ }^{15}$.

$\mathrm{O}$ indicador a respeito de disputa pela cadeira possui formas diferentes de mensuração, derivadas, sobretudo, da forma de eleição dos parlamentares. No caso do Reino Unido e dos Estados Unidos, por exemplo, o sistema de votação distrital torna a competição pela cadeira quase automática (dada a magnitude mínima de uma cadeira em disputa) e centrada em dois (caso dos EUA) ou poucos (caso do Reino Unido) partidos.

Hibbing (1988) utiliza dois indicadores para o caso britânico. O primeiro, o número de cadeiras não disputadas (ou seja, em que haveria menos de dois competidores). Esta situação era frequente na Câmara dos Comuns Britânica até o princípio do Séc. XX, mas tornou-se residual ao longo do tempo (o que tornaria o indicador sem utilidade para o período atual). Para o período posterior, o autor utiliza como indicador a porcentagem de membros ingressantes que tenham disputado previamente a cadeira ${ }^{16}$.

No caso brasileiro, em que a composição dos poderes legislativos é feita por voto proporcional em lista aberta (não previamente hierarquizada pelo partido), a competição é menos delimitada. No caso da ALESP, 94 cadeiras estão em disputa em todo o Estado, podendo ser conquistadas por qualquer candidato, filiado a partido, que consiga o número mínimo de votos para atingir o quociente eleitoral (ou que esteja minimamente bem posicionado, em termos de voto, na lista de partido que atinja o quociente ${ }^{17}$ ). É possível, assim, verificar com maior precisão o nível de competição por uma vaga em cada pleito.

Assim, utilizou-se como indicador, neste trabalho, o número de candidatos por vaga a cada pleito, cotejado com o quociente eleitoral a cada eleição. Os dados estão dispostos no gráfico 4, abaixo:

\footnotetext{
${ }^{15}$ HIBBING (1988), p. 689. .

16 Segundo o autor, "A growing percentage of members who have had at least one unsuccessful attempt to enter the House would be consistent with Polsby's notions that in an institutionalized legislature there is a "channeling" of careers and a need to "pay dues" or perform homage before entry is granted and advancements are made. All this relates to the idea that a part of institutionalization is the presence of obstacles that must be cleared in order to enter the institutionalized body" (pp. 689-690).

${ }^{17}$ Fonte: TRE-SP
} 


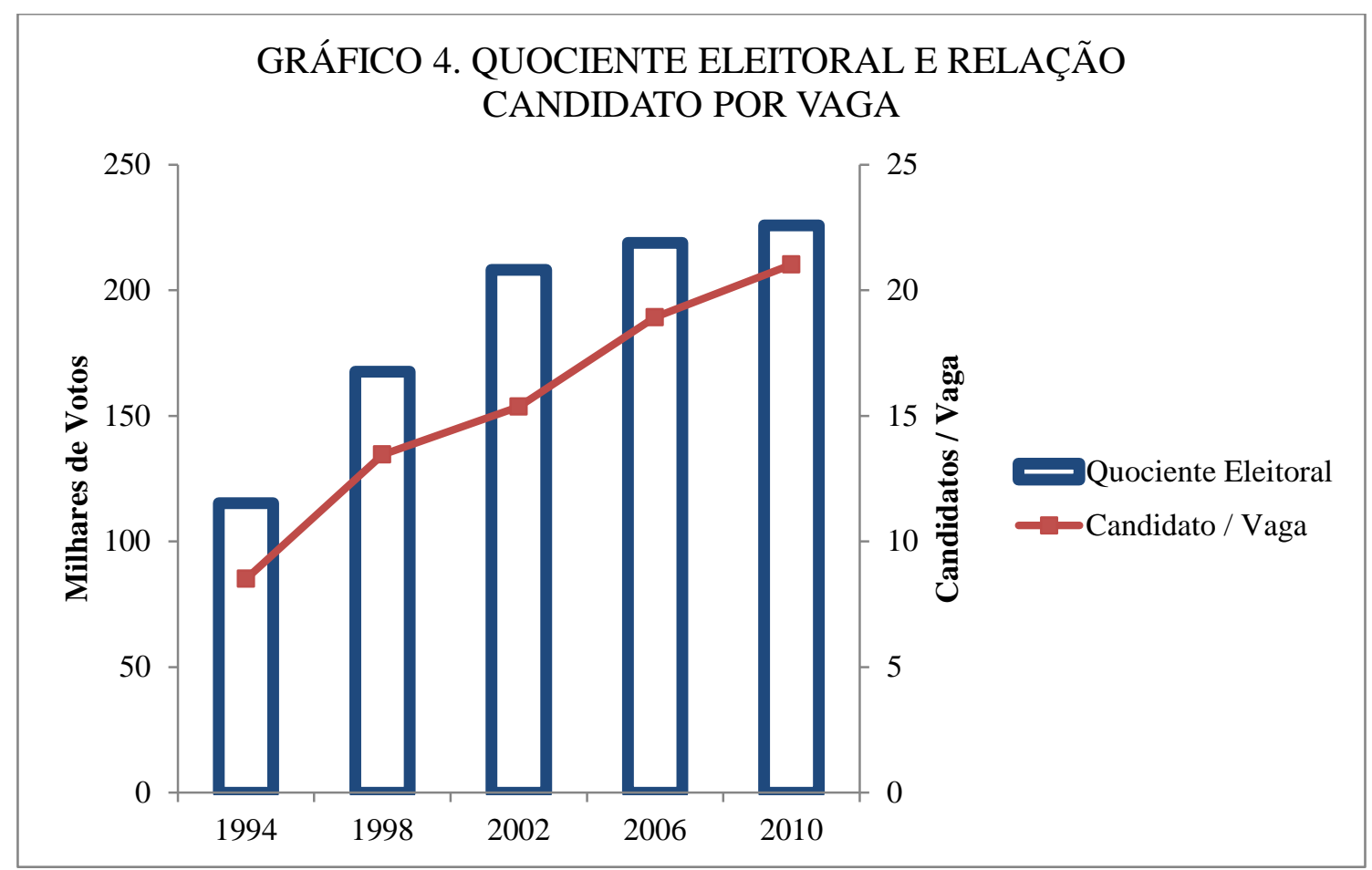

Fonte: TSE.

Como se pode perceber, é crescente o nível de competição para o cargo de deputado estadual em São Paulo. O número de candidatos por vaga aumenta 2,5 vezes no período. As cadeiras tornam-se mais disputadas em um contexto de maiores "custos" em termos de votos, já que, ainda que com menor tendência de crescimento nos três últimos pleitos (possivelmente, em razão das tendências demográficas declinantes ${ }^{18}$ ), o quociente eleitoral praticamente dobrou desde 1994.

Vale lembrar, neste caso, que a alta relação de candidatos por vaga não significa, por si só, competição efetiva pela cadeira (dado que muitos candidatos e partidos são tão somente figurantes no processo eleitoral). Ainda assim, o alto número de candidaturas, se entendido enquanto "vontade de pertencimento" a uma organização em função de sua importância, pode ser considerado elemento relevante de tendência à institucionalização.

\section{Presença de Mulheres}

Squire \& Hamm (2005, pp. 136-139) analisam elementos das carreiras de legisladores para além de mandatos, renovação e lideranças. Um dos elementos observados é a evolução na presença de mulheres e minorias.

18 De acordo com dados do Censo 2010 do IBGE, a taxa de fecundidade no Brasil diminuiu 21,9\% em 10 anos: de uma média de 2,38 filhos por mulher em 2000 para 1,86 em 2010. Em São Paulo, foi encontrada a segunda menor taxa média de fecundidade do Brasil, de 1,63 filhos por mulher (IBGE, 2011). 
Ao efetuar estudo semelhante, observamos, conforme o quadro 2, abaixo, que o nível de participação de mulheres no parlamento paulista permanece em níveis acentuadamente baixos.

\begin{tabular}{|c|c|c|c|c|c|}
\hline \multicolumn{6}{|c|}{ QUADRO 2. PRESENÇA DE MULHERES NA ALESP (ELEITAS) } \\
\hline Pleito & $\mathbf{1 9 9 4}$ & $\mathbf{1 9 9 8}$ & $\mathbf{2 0 0 2}$ & $\mathbf{2 0 0 6}$ & $\mathbf{2 0 1 0}$ \\
\hline $\mathbf{\%}$ & $11,7 \%$ & $7,4 \%$ & $10,6 \%$ & $11,7 \%$ & $10,6 \%$ \\
\hline $\mathbf{N}$ & 11 & 7 & 10 & 11 & 10 \\
\hline
\end{tabular}

Fonte: TSE

A participação média de $10,4 \%$ em todo o período demonstra estabilidade (o desvio-padrão é de apenas $0,02 \%$ ). Diversos estudos procuram lidar com a questão da baixa participação feminina nos espaços representativos brasileiros. Fatores como o financiamento eleitoral, os preconceitos enfrentados previamente pelas candidatas e a ausência de mecanismos de promoção da participação são apontados em diferentes trabalhos ${ }^{19}$.

Em comparação, Squire \& Hamm (Idem) encontraram um cenário mais igualitário em termos de gênero nos parlamentos subnacionais dos EUA. Segundo os autores, a partir dos anos 1970 o número de representantes do sexo feminino praticamente triplicou, saltando de pouco mais de seiscentas para quase 1700 mulheres eleitas para cargos legislativos em todo o país (cerca de $22 \%$ do total de cadeiras legislativas estaduais). Apontam, ainda, a presença maior de mulheres (e ocupação de posições de maior destaque) no âmbito subnacional em relação ao Congresso Nacional dos EUA.

Ainda para fins de comparação, o Congresso Nacional brasileiro tem atualmente um quadro semelhante de composição, com 47 deputadas $(9,1 \%$ do total) e 8 senadoras $(9,8 \% \text { do total })^{20}$.

\section{CONSIDERAÇÕES FINAIS}

Neste trabalho procurou-se apresentar e analisar sinteticamente alguns indicadores de institucionalização aplicados a um parlamento subnacional brasileiro - no caso, a Assembleia Legislativa do Estado de São Paulo (ALESP). Conforme discutido na introdução, há ainda um déficit considerável de trabalhos sobre órgãos legislativos em

${ }^{19}$ Ver ARAÚJO (2010) e SACCHET \& SPECK (2012).

${ }^{20}$ Fontes: Portais da Câmara dos Deputados e do Senado Federal. 
contextos subnacionais, além de uma ênfase grande da literatura na dinâmica de interação institucional entre os poderes Executivo e Legislativo. Assim, este artigo é uma pequena contribuição para um campo ainda pouco explorado pela literatura.

Os dados e informações apresentados na seção anterior parecem demonstrar tendência de maior institucionalização da ALESP nas últimas duas décadas, se observados à luz da literatura citada. Taxa de renovação estável (e com tendência de queda), seleção de lideranças experientes, incremento da disponibilidade de recursos e aumento do nível de competição pelas cadeiras seriam amostras desta situação.

Por outro lado, diversos autores questionam a linearidade entre alguns índices expressivos (como baixa taxa de renovação, por exemplo) e maior institucionalização. Hibbing (1999), por exemplo, questiona a relação entre turnover e institucionalização. Para o autor, uma organização pode ser capaz de lidar com altas taxas de renovação, desde que consiga aplacar os efeitos e impactos da maior rotatividade. Ainda segundo esse autor, uma instituição incapaz de lidar com a mudança (dependente, portanto, da permanência por maior tempo possível de seus quadros) seria, "ironicamente", menos institucionalizada ${ }^{21}$.

Outro ponto levantado pelo autor é a relação, por assim dizer, complexa, entre profissionalização e institucionalização. Os termos, geralmente tratados como intercambiáveis, possuem diferenças importantes: profissionalização seria o conjunto de estruturas e recursos materiais disponíveis a uma organização, ao passo que institucionalização seria um processo mais amorfo e complexo de construção de processos internos padronizados, autonomia institucional e ascensão de lideranças ${ }^{22}$. Logo, há que se verificar se os elementos de profissionalização presentes em um parlamento estão correlacionados ou induzem efetivamente ao processo de institucionalização ${ }^{23}$.

O ambiente institucional de interação dos parlamentos também deve ser considerado. Hibbing (1999), mais uma vez e a título de exemplo, aponta a importância de se considerarem diferenças entre sistemas parlamentaristas e presidencialistas na observação de diferentes formas de institucionalização, além de outros possíveis arranjos constitucionais / legais que induzem a tipos específicos de construção institucional ${ }^{24}$. Nesta linha, Silva (2012) encontrou um panorama pouco promissor ao analisar a produção legislativa e a formação de coalizões no âmbito da ALESP - panorama este, segundo o autor, diretamente relacionado com o arcabouço federativo nacional. A Constituição Federal, ao tornar algumas matérias legislativas privativas da União, diminuiu,

\footnotetext{
${ }^{21}$ HIBBING (1999), p. 158.

22 Idem, p. 162.

${ }^{23}$ Nas palavras do autor, “(...) professionalization often, but not always, lead to institutionalization”. (Idem, p. 163).

${ }^{24}$ Idem, pp. 160-163.
} 
consideravelmente, o espaço de atuação das assembleias estaduais. Além disso, a maior parte das matérias estaduais são de iniciativa privativa do Executivo, o que diminui ainda mais a margem de atuação dos parlamentos. Dessa forma, segundo o autor, a capacidade de influência dos Legislativos estaduais seria fortemente constrangida pelo arranjo federativo brasileiro. O cenário encontrado pelo autor foi de uma ALESP com capacidade diminuta de emendamento legislativo e intervenção na agenda política estadual.

Conforme visto na seção anterior, a presença de mulheres na ALESP (assim como em diversos legislativos e cargos decisórios da política brasileira ${ }^{25}$ ) tem tendência estável de baixa participação. Ainda que não efetuado neste trabalho, um estudo sobre presença de outras minorias (como pretos, pardos e indígenas) possivelmente apresentaria resultados semelhante. Foge ao escopo deste trabalho discutir as definições tortuosas da representação. De qualquer maneira, a capacidade de absorção por uma instituição de certas demandas e anseios da sociedade deveria ser normativamente esperada. Dito de outro modo: se entendida a institucionalização apenas como manutenção (ou conservação?) e incremento de determinadas práticas, costumes e situações, provavelmente sua relação com o ambiente tenderá a tornar-se cada vez mais distante. Neste contexto, caberia repetir a indagação de Hibbing (1988, p. 164): afinal, a institucionalização é desejável? Ainda melhor: qual institucionalização seria desejável?

$\mathrm{Na}$ literatura sobre burocracia e padrões de interação entre Estado e sociedade, um conceito geralmente utilizado é o de insulamento ${ }^{26}$. Sua acepção recorrente é semelhante ao conceito de institucionalização: autonomia perante o ambiente que o cerca, a profissionalização técnica de seus quadros e critérios universais de procedimentos.

O avanço de um quadro desta ordem, porém, pode ter consequências não previstas e deletérias: bloqueio às mudanças e impermeabilidade aos determinantes oriundos de um ambiente externo. A institucionalização / insulamento, neste caso, seria sinônimo de descolamento e quase-independência de uma organização ${ }^{27}$.

Resta, portanto, o desafio (teórico e, por que não dizer, político-normativo) de encontrar um termo adequado entre a institucionalização enquanto fortalecimento organizacional de órgão essencial à democracia, por um lado; e a autopreservação insulada e pouco efetiva de estruturas decisórias, de outro. O aprofundamento de pesquisas e

\footnotetext{
${ }^{25}$ De acordo com Sachet \& Speck (2012), o Brasil é o segundo país da América Latina com mais baixas taxas de participação feminina nos cargos legislativos federais.

${ }^{26}$ Sobre o conceito e suas aplicações, ver NUNES (1997) e MOURA FÉ (2003).

${ }^{27}$ HIBBING (1999), pp. 164-166.
} 
estudos neste campo (sobretudo a partir de casos ainda incipientes na literatura, como os parlamentos subnacionais brasileiros) poderá apontar pistas neste caminho.

\section{REFERÊNCIAS BIBLIOGRÁFICAS}

ABRANCHES, S. Presidencialismo de Coalizão: O Dilema Institucional Brasileiro. Dados, vol. 31, no 1, pp. 5-34, 1988.

ALESP. Legislativo Paulista: Parlamentares - 1835-2003. São Paulo: Imprensa Oficial, 1998.

ALESP. Galeria dos presidentes da Assembleia Legislativa de São Paulo. São Paulo: ALESP, 2006.

AMES, B. Os Entraves da Democracia no Brasil. Rio de Janeiro, FGV, 2003.

ARANTES, R.B. Ministério Público na Fronteira entre a Justiça e a Política. Justitia, v. 197, pp. 325-335, 2007.

ARAÚJO, C. Rotas de Ingresso, Trajetórias e Acesso das Mulheres ao Legislativo - Um Estudo Comparado entre Brasil e Argentina. Estudos Feministas, Vol. 18, n 2, pp. 567-584, 2010.

CHAFFEY, D.C. The Institutionalization of State Legislatures: A Comparative Study. The Western Political Quarterly, Vol. 23, no. 1, pp. 180-196, 1970.

FIGUEIREDO, A. \& LIMONGI, F. Executivo e Legislativo na nova Ordem Constitucional. Rio de Janeiro: FG, 1999.

HIBBING, J.R. Legislative Institutionalization with Illustrations from the British House of Commons. American Journal of Political Science, Vol. 32, n 3, pp. 681-712, 1988.

HIBBING, J.R. Legislative Careers: Why and How We Should Study Them. Legislative Studies Quarterly, Vol. 24, n 2, pp. 149-171, 1999.

IBGE. Censo 2010: País tem declínio de fecundidade e migração e aumentos na escolarização, ocupação e posse de bens duráveis. Disponível em: http:/ $/$ saladeimprensa.ibge.gov.br/noticias? view $=$ noticia\&id $=1 \&$ busca $=1 \& i d n o t i c i a=2018$ (Acesso em 01.05.2013).

LAMOUNIER, Bolívar. Estrutura institucional e governabilidade na década de 90 . In: VELLOSO, J.P.R. (org.). O Brasil e as reformas políticas. Rio de Janeiro: José Olympio, 1992.

LUZ, R. B. A institucionalização da Câmara Legislativa do Distrito Federal. Dissertação de Mestrado (IPOL/UNB). Brasília, 2009.

MOURA FÉ, C.F.C. Agências Reguladoras e Reforma do Estado Brasileiro: Insulamento Burocrático ou Democratização do Estado? Um Estudo Multicaso (Aneel, Anatel, Anvisa e Ans). Dissertação de Mestrado (EBAP/FGV). Rio de Janeiro, 2003. 
NUNES, E. O. Gramática Política do Brasil: Clientelismo e Insulamento. Rio de Janeiro: Zahar, 1997.

PALLANZA, V.; SCARTASCINI, C.; TOMMASI, M. On the Institutionalization of Congress(es) in Latin America and Beyond. Washington: IDB, 2012.

POLSBY, N. W. The Institutionalization of the U.S. House of Representatives. The American Political Science Review, Vol. 62, nº 1, pp. 144-168, 1968.

ROSENTHAL, A. State Legislative Development: Observations from Three Perspectives. Legislative Studies Quarterly, vol. 21, nº. 2, pp. 169-198, 1996.

SACCHET, T. \& SPECK, B. W. Financiamento eleitoral, representação política e gênero: uma análise das eleições de 2006. Opinião Pública, vol. 18, n 1, pp. 177-197, 2012.

SAMUELS, D. Ambition and Competition: Explaining Legislative Turnover in Brazil. Legislative Studies Quarterly, Vol. 25, nº 3, pp. 481-497, 2000.

SILVA, F.L.M. Presidencialismo Estadual e Participação Legislativa em São Paulo (1999-2010). Dissertação de Mestrado (FFLCH/USP). São Paulo, 2012.

SILVA JÚNIOR, J. A. \& FIGUEIREDO FILHO, D. B. Marolas ou Tsunamis? O Impacto das Ondas de Renovação sobre a Profissionalização dos Deputados Federais (1999-2003). Revista de Sociologia e Política, Vol. 20, nº 42, pp. 199-212, 2012.

SQUIRE, P. The Theory of Legislative Institutionalization and the California Assembly. The Journal of Politics, vol. 54, nº.4, pp. 1026-1054, 1992.

SQUIRE, P. \& HAMM, K. 101 Chambers: Congress, States Legislatures and the Future of Legislative Studies. Columbus: Ohio State University, 2005.

\section{Sítios}

Departamento Intersindical de Assessoria Parlamentar - www.diap.org.br

Câmara dos Deputados - www.camara.gov.br

Senado Federal - www.senado.gov.br

Sistema Integrado de Administração Fazendária - Secretaria da Fazenda do Estado de São Paulo - http://www.fazenda.sp.gov.br/cge2/balanco.asp?tipo $=0$

Tribunal Regional Eleitoral de São Paulo - www.tre-sp.jus.br

Tribunal Superior Eleitoral - www.tse.jus.br 